\title{
Ação antioxidante do Ácido Ascórbico na toxicidade do catecol em células da linhagem GL-15
}

\author{
Antioxidant action of ascorbic acid against catechol-induced toxicity on GL-15 cells
}

\author{
Maria Socorro Grangeiro ${ }^{1}$, Diego Madureira de Oliveira², \\ Ramon dos Santos El-Bachá ${ }^{3}$, Silvia Lima Costa ${ }^{4}$, Maria de Fátima Dias Costa ${ }^{5}$ \\ ${ }^{1}$ Bióloga. Doutoranda do Programa de Pós-Graduação Processos Interativos dos Órgãos e Sistemas, ICS - UFBA. \\ Professora da Secretaria de Educação e Cultura do Estado da Bahia. \\ ${ }^{2}$ Professor Adjunto. Programa de Pós-graduação em \\ Ciências da Saúde da Universidade de Brasília - UnB. \\ ${ }^{3}$ Professor Associado. Departamento de Biofunção, ICS - UFBA e Programas de Pós-Graduação em Química, \\ Instituto de Química - UFBA, e Patologia Humana - FIOCRUZ - BA. \\ ${ }^{4}$ Professora Associada. Departamento de Biofunção, ICS - UFBA e Programas de Pós-Graduação em Imunologia e \\ Ciência Animal nos Trópicos - UFBA \\ ${ }^{5}$ Professora Titular. Departamento de Biofunção e Programas de Pós-graduação Processos Interativos dos Órgãos e \\ Sistemas e Imunologia, ICS - UFBA.
}

\begin{abstract}
Resumo
Introdução: A toxicidade do Catecol está relacionada com a formação de quinonas seguido de promoção de apoptose, ambos os efeitos suprimidos pela superóxido dismutase. Objetivo: Neste trabalho foi estudada a ação antioxidante do ácido ascórbico em células GL-15 após o estresse oxidativo induzido pelo catecol, a fim de comparar os dados e gerar mais informações sobre a citotoxicidade do catecol nesta linhagem celular. Metodologia: Uma vez que trabalhos anteriores mostraram que o valor de IC50 nestas células foi de $230 \mu \mathrm{M}$, após 72 horas de exposição, foram utilizadas as concentrações de catecol desde $300 \mu \mathrm{M}$ até $600 \mu \mathrm{M}$. Conclusão: As concentrações sub-tóxicas de ácido ascórbico $(600 \mu \mathrm{M}-3000 \mu \mathrm{M})$ protegeram as células GL-15 contra danos oxidativos induzidos pelo catecol e reverteram completamente a formação de quinonas, confirmando que a toxicidade do catecol contra células GL-15 está essencialmente relacionada com a formação de quinonas reativas.

Palavras chave: Catecol. Quinona. Antioxidante. Citotoxicidade. Superóxido.

Abstract

Background: Catechol toxicity is related to quinone formation followed by promotion of apoptosis, both effects suppressed by superoxide dismutase. Objective: In this work the antioxidante action of ascorbic acid on GL-15 cells after catechol-induced oxidative stress was studied in order to compare the data and generate more information about the cytotoxicity of catechol in this cell line. Methodology: Since previous work showed that the IC50 value on these cells was $230 \mu \mathrm{M}$ after 72 hours exposition, catechol concentrations ranging from $300 \mu \mathrm{M}$ to $600 \mu \mathrm{M}$ were used. Conclusion: Sub-toxic concentrations of ascorbic acid (600 $\mu \mathrm{M}$ - 3000 $\mu \mathrm{M}$ ) protected GL-15 cells against oxidative damage induced by catechol and completely avoided quinone formation, confirming that the toxicity of catechol against GL-15 cell is mainly related to the formation of reactive quinones.

Keywords: Catechol. Quinone. Antioxidant, Cytotoxicity. Superoxide.
\end{abstract}

\section{INTRODUÇÃO}

O benzeno é um produto industrial químico importante que polui o ambiente de forma generalizada, ao ser metabolizado torna-se cancerígeno e é conhecido por seus metabólitos tóxicos induzirem doenças do sangue como leucemia e outras (XING et al., 2013). Substâncias aromáticas, tais como o benzeno, o tolueno, etilbenzeno e xileno constituem um sério risco para a saúde de trabalhadores da indústria petrolífera e petroquímica e de locais em que a gasolina é utilizada de forma contínua; a exposição ao benzeno é um problema sério, prin-

Correspondência / Correspondence: Maria Socorro Grangeiro. Rua Alberto Fiúla, no 270, Imbuí, Salvador-Ba. Cep: 41720-025 cipalmente no mundo industrializado moderno e sabe-se que os metabólitos deste agente são responsáveis pela sua toxicidade. (GLASS; GRAY, 2001; LEE; KANG; KWON, 2013; VAGHASIA, 2013). Foram avaliados os efeitos genotóxicos da exposição a baixos níveis de benzeno, um carcinógeno humano classe I, entre atendentes de postos de gasolina que apresentaram índices maiores de danos ao DNA, aumento do dano oxidativo de proteínas e diminuição da capacidade antioxidante em relação ao grupo controle e a duração da exposição ao benzeno foi correlacionada com genotoxicidade. (MORO et al., 2013). Existe uma ampla evidência de que a substância carcinogênica benzeno pode causar aberrações cromossômicas no esperma a níveis muito baixos de exposição 
e isso inclui exclusões cromossômicas que são conhecidas por causar infertilidade, retardo mental e malformações congênitas. (BONDE, 2013).

O metabolismo do benzeno pela fração microssomal hepática resulta na formação de catecóis (POWLEY; CARLSON, 1999; VAGHASIA, 2013), substâncias responsáveis por sua toxicidade. A principal causa de câncer de pulmão é a exposição à fumaça de cigarro e outros poluentes ambientais dentre esses o formaldeído, acroleína, benzeno, dioxinas e hidrocarbonetos aromáticos policíclicos, implicando em risco para fumantes (TSAY et al., 2013). Sabe-se que a exposição de trabalhadores ao benzeno na indústria petrolífera é uma causa de câncer do sistema linfo-hematopoiético. $O$ benzeno penetra facilmente no cérebro, onde é metabolizada a catecol.

A vitamina C, ácido ascórbico, uma vitamina solúvel em água e que está presente em frutas cítricas e vegetais, é importante devido as suas ações antioxidantes, como removedor de radicais livres, bem como um co-fator em reações de hidroxilação. Os seres humanos são incapazes de sintetizar o ácido ascórbico, portanto, sua ingestão dietética é essencial. $O$ interesse em vitamina $C$ como um ingrediente em cosmético é em parte resultado da mesma capacidade de eliminar os radicais livres induzidos diretamente por radiações ultravioletas e para regenerar a vitamina $E$, outro potente antioxidante (DARR et al., 1992; CHAN et al., 1993). A vitamina C é também considerada um ingrediente antienvelhecimento devido ao seu potencial para estimular a produção de colágeno e por isso é utilizada em produtos cosméticos para proteger e reduzir os sinais de envelhecimento, principalmente devido às suas propriedades antioxidantes (PHILLIPS et al., 1994; LUPO, 2001). Observou-se que em sistema aquoso o Ácido Ascórbico teve o melhor potencial antioxidante que Magnésio Ascorbil Fosfato (MAP) e Ascorbil Tetra Iso Palmitato (ATIP) quando utilizados em cosméticos (MAIA CAMPOS et al., 2008) e ainda a vitamina $C$ foi sugerida para reduzir o estresse oxidativo em indivíduos com gastrite atrófica (SASAZUKI et al., 2008) corroborando o potencial antioxidante da Vitamina C, EL-Bachá; Lima-Filho; Guedes (1998) demonstraram em modelos in vivo de ratos da linhagem Wistar que uma dieta deficiente de antioxidantes como Vitamina C e Vitamina E facilita a Depressão Alastrante Cortical induzida por Riboflavina fotoativada.

Células de origem glial podem ser cultivadas como linhagens celulares e podem constituir modelos alternativos confiáveis para o estudo de propriedades e resposta de células gliais a agentes externos (LAL; GHIRNIKAR; ENG, 1996). As células gliais, principalmente astrócitos, podem transformar-se em astrocitomas malignos e serem distintos em grau de malignidade crescente segundo os critérios da OMS, sendo o grau IV o mais agressivo, os chamados glioblastomas multiformes (HILDEBRAND; WITTE; SAHMOUD, 1998). As linhagens de células de glioblastomas são utilizadas para estudos experimentais, pois são facilmente acessíveis, manipulá- veis e oferecem resultados reprodutíveis mais rapidamente. A linhagem GL-15 foi estabelecida e caracterizada por (BOCCHINI et al., 1991) a partir de glioblastoma multiforme humano. Segundo estes autores, esta é uma linhagem clonal, cuja análise do cariótipo revelou uma grande instabilidade cromossômica, com anomalias numéricas e estruturais, e o estudo da cinética do crescimento mostra que o tempo de duplicação das células GL-15 é de 30 a 48 horas. 0 presente estudo examinou o efeito antioxidante do ácido ascórbico em um modelo de estresse oxidativo promovido pelo catecol em células de glioblastoma humano GL-15 (PEREIRA et al., 2004) a fim de fornecer mais informações sobre os efeitos deletérios de compostos aromáticos e a ação de antioxidantes exógenos para o SNC.

\section{MATERIAIS E MÉTODOS}

Para o desenvolvimento desse trabalho foi necessária utilização de celulas da linhagem Gl15 glioblastomas multiformes humanos (BOCCHINI et al., 1991). O potencial antioxidante do ácido ascórbico em culturas destas células foi estudado através de curvas de proliferação, viabilidade e integridade celular e empregando-se o brometo de 3- (4,5-dimetilazol-2-il)-2,5-difeniltetrazólum (MTT) enquanto substrato para as desidrogenases mitocondriais (LIU et al., 2013).

\section{Cultura de células de glioblastoma}

A linhagem GL-15 (BOCCHINI et al., 1991), derivada de glioblastoma multiforme humano foram cultivadas até confluência em placas de poliestireno de 35 milímetros de diâmetro ou nas placas de 96 poços a uma densidade de 104 células/cm2, em meio DMEM, suplementado com $100 \mathrm{Ul} / \mathrm{ml}$ de penicilina $\mathrm{G}, 100 \mathrm{mg} / \mathrm{ml}$ de estreptomicina, $7 \mathrm{mM}$ de glicose, $2 \mathrm{mM}$ de glutamina, 0,011 g/l de piruvato, e 10\% de Soro fetal Bovino, e as culturas foram mantidas em uma atmosfera úmida com $5 \%$ de $\mathrm{CO} 2$ a 37 ㅇ․ .

\section{Drogas e tratamentos \\ Testes do catecol, e do ácido ascórbico em célu-} las gliais.

As células confluentes foram tratadas com catecol na concentração IC50 estabelecida previamente por Pereira e col. (2004) e com ácido ascórbico em concentrações de 20 a $3000 \mu \mathrm{M}$ em placas de 96 poços variando-se a concentração por períodos de $72 \mathrm{~h}$ a fim de se avaliar a ação antioxidante do ácido ascórbico. Esta variação está de acordo com dados da literatura que mostram a concentração deste composto variando entre 90 a $9000 \mu \mathrm{M}$ em pessoas expostas (BUKOWSKA; KOWALSKA, 2004). Esses estudos foram feitos, tendo como grupo controle negativo células tratadas com o diluente do catecol, $\mathrm{HCl}\left(2 \times 10^{-5} \mathrm{M}\right)$. Estudos preliminares mostram que o solvente nas referidas concentrações não induzem toxicidade. Para o teste de citotoxicidade e de ação antioxidante as células de glioblastoma das linhagens GL- 
15 foram cultivadas em placas de 96 poços. As células foram expostas às drogas e duas horas antes do término do tempo de exposição, o meio de cultura foi substituído por uma solução (MTT), diluído em DMEM $(1 \mathrm{mg} / \mathrm{ml})$ mantendo-se as placas por duas horas a $37^{\circ} \mathrm{C}$. Para a dissolução dos cristais de formazan formados pela ação das desidrogenases mitocondriais sobre o substrato MTT, foi acrescido um volume de tampão de lise (20\% SDS, 50\% DMF, pH 4,7), mantendo-se as placas por 24 horas a temperatura ambiente. A absorbância óptica de cada amostra foi medida usando um espectrofotômetro BIO-RAD 550PLUS em um comprimento de onda de $580 \mathrm{~nm}$.

\section{Análise estatística dos resultados}

Cada variável experimental foi feita em quadruplicata e em três experimentos independentes e os resultados expressos pela média e desvio padrão. Nos casos em que os grupos tiverem distribuição normal a análise dos resultados foi feita usando-se o teste ANOVA One Way seguido do teste de Student-Newmann-Keuls. Quando o teste de normalidade falhou os resultados foram expressos pela mediana e percentis, sendo utilizado ANOVA on ranks, seguido pelo teste de Dunnett para análise dos dados. Valores de $\mathrm{p}<0,005$ foram considerados como estatisticamente significantes.

\section{RESULTADOS}

\section{Ácido ascórbico}

O ácido ascórbico (Figura 1) não apresentou toxicidade em células de GL-15 nas concentrações testadas: $(20 \mu \mathrm{M}-3000 \mu \mathrm{M})$.

Figura 1. Curva de viabilidade celular demonstrando a ação do ácido ascórbico em GL-15 (dados do teste de MTT) após 72 horas de tratamento.

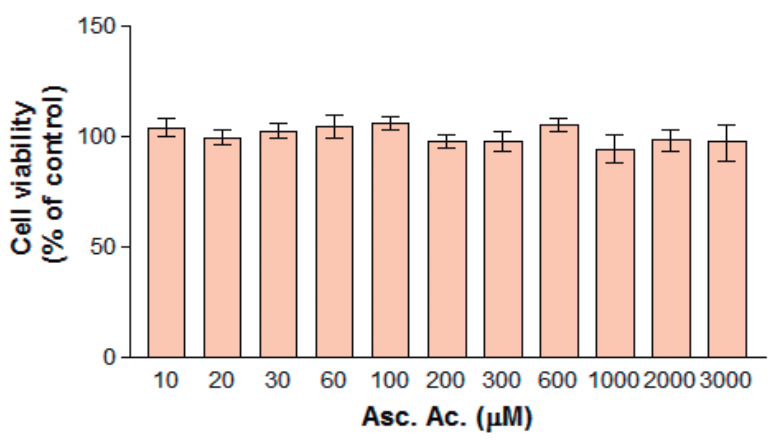

Avaliação da ação antioxidante do ácido ascórbico na lesão oxidativa induzida pelo catecol em GL-15.

O Ácido ascórbico exerceu ação antioxidante em culturas de células da linhagem GL-15 submetidas à lesão oxidativa induzida pelo catecol com 72 h. O Ácido ascórbico nas concentrações de $20 \mu \mathrm{M}-300 \mu \mathrm{M}$ protegeu parcialmente e nas concentrações de $600 \mu \mathrm{M}$ $3000 \mu \mathrm{M}$ protegeu totalmente as células GL-15 do dano celular induzido pelo catecol e indica aumento de proliferação celular (Figura 2).
Figura 2. Curva dose-resposta demonstrando a ação antixidante pelo ácido ascórbico em GL-15 (dados do teste do teste do MTT) induzidas à lesão oxidativa pelo catecol com 72 horas de tratamento.

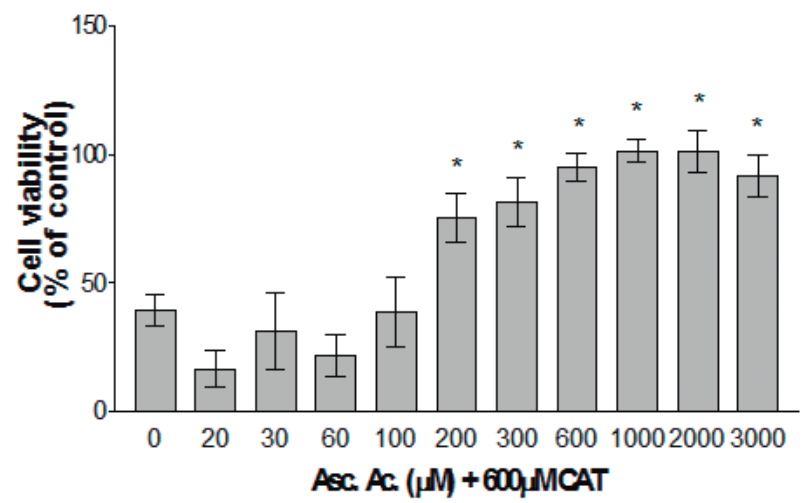

Redução da formação de quinonas promovida por ácido ascórbico em GL-15 tratadas com catecol por 72 horas.

O ácido ascórbico reduziu parcialmente a formação de quinonas reativas (Figura 3) na citotoxicidade induzida pelo catecol em células de GL-15, nas concentrações $(20 \mu \mathrm{M}-300 \mu \mathrm{M})$ e nas concentrações (600 $\mu \mathrm{M}$ - $3000 \mu \mathrm{M}$ ) essa redução foi total (Figura 4). Confirmando a sua ação antioxidante nesse modelo de estresse oxidativo.

Figura 3. Curva dose-resposta demonstrando a redução de quinonas pelo ácido ascórbico em GL-15 (dados do teste do teste do MTT) induzidas à lesão oxidativa pelo catecol com 72 horas de tratamento.

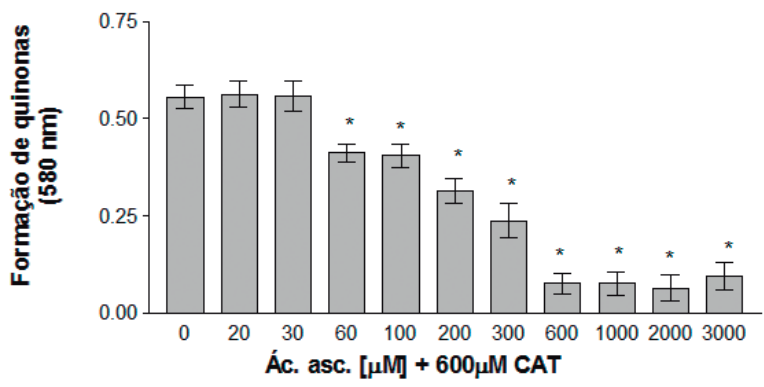

Figura 4. Imagens demonstrando a ação do ácido ascórbico contra alterações morfológicas induzidas pelo catecol em GL15 com 72 horas de exposição às drogas. Cada espaço da régua corresponde a $10 \mu \mathrm{M}$.
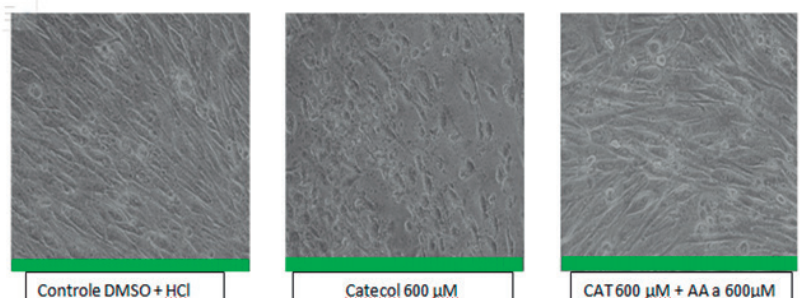


\section{DISCUSSÃO}

A linhagem GL-15 foi estabelecida e caracterizada por Bocchini et al., (1991) a partir de glioblastoma multiforme humano. Segundo estes autores, esta é uma linhagem clonal, cuja análise do cariótipo revelou uma grande instabilidade cromossômica, com anomalias numéricas e estruturais, e o estudo da cinética do crescimento mostra que o tempo de duplicação das células GL-15 é de 30 a 48 horas. Células derivadas de tumor, assim como linhagem celular de glioblastoma, têm sido largamente usadas para estudar as propriedades dos astrócitos (BRISMAR, 1995). Nós usamos células de glioblastoma humano da linhagem GL-15 para avaliar a citotoxicidade e a ação antioxidante de compostos. O cérebro é particularmente vulnerável ao estresse oxidativo devido da sua taxa elevada de metabolismo oxidativo ( $20 \%$ de absorção total de oxigênio apesar de seu tamanho relativamente pequeno) e reduzida capacidade para regeneração celular comparado a outros órgãos. Doenças neurodegenerativas de fisiopatologia distintas são conhecidas por compartilhar características bioquímicas comuns, tais como a disfunção mitocondrial e dano celular induzida por estresse oxidativo (HALLIWELL, 2006) e estimular processos inflamatórios, desencadeando uma cascata de eventos levando à morte celular por apoptose em desordens neurodegenerativas. (KE; QIAN, 2003; BARNHAM et al., 2004). Portanto, o desenvolvimento de agentes antioxidantes que sejam capazes de modular mecanismos de remoção de radicais livres, sem interferir em qualquer mecanismo fisiológico essencial com base na sinalização celular, é uma abordagem promissora contra neurodegeneração. (CONTESTABILE, 2001; ZUO; MOTHERWELL, 2013).

Nesse trabalho estudou-se a ação antioxidante do ácido ascórbico em células da linhagem GL-15 induzidas ao estresse oxidativo pelo catecol. As concentrações empregadas do catecol variaram entre 300 e $600 \mu \mathrm{M}$. Em trabalho realizado por Pereira e col. (2004), estudou-se a citotoxicidade do catecol para células de glioblastoma multiforme humano da linhagem GL-15. O catecol foi tóxico após 72 horas e essa toxicidade relacionou-se com a formação de quinonas. O catecol a $230 \mu \mathrm{M}$ matou metade das células em cultura. A toxicidade do catecol e a produção de quinonas foram inibidas por $100 \mathrm{U}$ de superóxido dismutase e ainda em trabalho realizado por Madureira e col. O catecol induz morte por apotose em células da linhagem GL-15. O Ácido ascórbico não apresentou toxicidade contra células de GL-15 em altas concentrações e protegeu essas células contra o dano oxidativo induzido pelo catecol. A Vitamina $\mathrm{C}$ um antioxidante natural é conhecido por reduzir o risco de desordens neurodegenerativas tais como a doença de Alzheimer (PERRIG et al., 1997; MASAKI et al., 2000).

Com a finalidade de confrontar os dados e ampliar o arsenal de informações acerca da citotoxicidade do catecol nesta linhagem celular, nesse trabalho foi utilizado o ácido ascórbico para demonstrar a atividade an- tioxidante. $\mathrm{O}$ ácido ascórbico nas concentrações sub-tóxicas de 600 a $3000 \mu \mathrm{M}$ protegeu totalmente células GL-15 induzidas ao dano oxidativo pelo catecol e reverteu totalmente a formação de quinonas, demonstrando que a toxicidade do catecol contra células GL-15 está relacionada principalmente com a formação de quinonas reativas.

\section{REFERÊNCIAS}

BARNHAM, K.J.; MASTERS, C.L.; BUSH, A.I. Neurodegenerative diseases and oxidative stress. Nat. Rev. Drug. Discov., London, v. 3, n. 3, p. 205-14, 2004.

BOCCHINI, V. et al. Changes in GFAP and Karyotype during culturing of two cell lines estabilished from human glioblastoma multiform. Cell Tissue Res., Berlin, v. 265, n. 1, p. 73-81, 1991.

BONDE, J.P. Occupational causes of male infertility. Curr. Opin. Endocrinol. Diabetes Obes., London, v. 20, n. 3, p. 234-9, 2013.

BRISMAR, T. Physiology Of Transformed Glial Cells. Glia., New York, v. 15, n. 3, p. 231-243, 1995.

BUKOWSKA, B.; KOWALSKA, S. Phenol and catechol induce prehemolytic and hemolytic changes in human erythrocytes. Toxicol. Lett., Amsterdam, v. 152, n. 1, p. 73-84, 2004.

CHAN, A.C. Partners in defense, vitamin E and vitamin C. Con. J. Physiol. Pharmacol., Ottawa, v. 71, n. 9, p. 725-31, 1993.

CONTESTABILE, A. Oxidative stress in neurodegeneration: mechanisms and therapeutic perspectives. Curr. Top. Med. Chem., Hilversum, v. 1, n. 6, p. 553-68. 2001.

DARR, D. et al. Topical vitamin C protects porcine skin from ultraviolet radiation-induced damage. Br. J. Dermatol., Oxford, v. 127, n. 3, p. 247-53, 1992.

EL-BACHÁ, R.S.; LIMA-FILHO, J.L.; GUEDES, R.C.A. Dietary Antioxidant Deficiency facilate cortical spreading depression induced by photoactivated riboflavin. Nutritional Neroroscience, Leeds, v. 1, p. 205-202, 1998.

GLASS, D.C.; GRAY, C.N. Estimating mean exposures from censored data: exposure to benzene in the Australian petroleum industry. Ann. Occup. Hyg., Oxford, v. 45, n. 4, p. 275-582, 2001.

HALLIWELL, B. J. Oxidative stress and neurodegeneration: where are you now? J. Neurochem., Oxford, v. 97, n. 6, p. $1634-58,2006$.

HILDEBRAND, J.; WITTE, O.; SAHMOUD, T. Response of recurrent glioblastoma and anaplastic astrocytoma to dibromodulcitol, BCNU and procarbazine--a phase-II study. J. Neurooncol., Dordrecht, v. 37, n. 2, p.155-60, 1998

KE, Y.; QIAN, M.Z. Iron misregulation in the brain: a primary cause of neurodegenerative disorders. Lancet Neurol., London, v. 2, n. 4, p. 246-53. 2003.

LAL, P.G.; GHIRNIKAR, R.S.; ENG, L.F. Astrocyte-Astrocytoma Cell Line Interacions in Culture. J. Neurosci. Res., New York, v. 44, n. 3, p. 216222, 1996.

LEE, S.Y.; KANG, H.J.; KWON, J.H. Toxicity cutoff of aromatic hydrocarbons for luminescence inhibition of Vibrio fischeri. Ecotoxicol. Environ. Saf., New York, v. 94, p.116-22, 2013.

LIU, D. M. et al. Acetylpuerarin increases cell viability and reduces apoptosis in rat hippocampal neurons following oxygen glucose depri- 
vation/reperfusion. Mol. Med. Rep., Athens, v. 8, n. 5, p. 1453-9, 2013.

LUPO, M.P. Antioxidants and vitamins in cosmetics. Clin. Dermatol., Philadelphia, v. 19, n. 4, p. 467-473, 2001.

MAIA, C.P.M.B.G.; GONÇALVES, G.M.; GASPAR, L.R. In vitro antioxidant activity and in vivo efficacy of topical formulations containing vitamin $\mathrm{C}$ and its derivatives studied by non-invasive methods. Skin Res.Technol., Copehnagen, v. 14, n. 3, p.376-380, 2008.

MASAKI, K.; H. et al. Association Of Vitamin E And C Supplement Use With Cognitive Function And Dementia In Elderly Men. Neurology., Minneapolis, v. 54, n. 6, p. 1265-1272, 2000.

MORO, A.M. et al. Genotoxicity and oxidative stress in gasoline station attendants. Mutat. Res., Amsterdam, v. 14, n. 754, p. 63-70, 2013.

PEREIRA, M.R.G. et al. Cytotoxicity of cathecol towards human glioblastoma cells via superoxide and quinones generation. J. Bras. Patol. Med. Lab., Rio de Janeiro, v. 40, n. 4, p. 280-5, 2004.

PERRIG, W.J.; PERRIG, P.; STAHELIN, H.B. The relation between antioxidants and memory performance in the old and very old. J. Am. Geriatr. Soc., New York, v. 45, n. 6, p. 718-724, 1997.
PHILLIPS, C.L.; COMBS, S.B.; PINNELL, S.R. Effects of ascorbic acid on proliferation and collagen synthesis in relation to the donor age of human dermal fibroblasts. J. Invest. Dermatol., Baltimore, v. 103, n. 2, p. 228-32, 1994.

POWLEY, M.W.; CARLSON, G.P. Species comparison of hepatic and pulmonary metabolism of benzene. Toxicology., Amsterdam, v. 139, n. 3, p. 207-217, 1999.

SASAZUKI, S. et al. Protective effect of vitamin C on oxidative stress: a randomized controlled trial. Int. J. Vitam. Nutr. Res., Bern, v. 78, n. 3, p. 121-8, 2008.

TSAY, J.J. et al. Aryl hydrocarbon receptor and lung cancer. Anticancer Res., Athens, v. 33, n. 4, p.1247-56, 2013.

VAGHASIA, K.K. et al. Renal and hepatotoxic alterations in adult mice on inhalation of specific mixture of organic solvents. Toxicol. Ind. Health., London, 2013.

XING, C. et al. Microsomal epoxide hydrolase (EPHX1) polymorphisms are associated with aberrant promoter methylation of ERCC3 and hematotoxicity in benzene-exposed workers. Environ. Mol. Mutagen., New York, v. 54, n. 6, p. 397-405, 2013.

ZUO, L.; MOTHERWELL, M.S. The impact of reactive oxygen species and genetic mitochondrial mutations in Parkinson's disease. Gene., Amsterdam, v. 532, n. 1, p. 18-23, 2013.

Submetido em 13.11.2013;

Aceito em 20.12.2013. 